\title{
Supplier evaluation in industrial power services: a case study in gas-turbine maintenance, repair, and overhaul
}

\author{
Yordian Fachrie*, Arviansyah \\ Faculty of Economics and Business, Indonesia University
}

\begin{abstract}
The maintenance is one of the highest costs in a gas-turbine engine, after operating cost with approximately about $14-19 \%$ of the total cost. Some of the operators do not have spare engines, and it will lead to operation shutdown. With the current market, most MRO challenged to provide their costumer to achieve quick turnaround time (TAT) at a low cost without affecting the quality of the product. Since MRO is selling the skill services, it took applied technology, skill training, and experience to deliver quality, which needs high cost. Therefore, MRO needs to collaborate with other parties (original manufacturer or others) to increase its capacity and capability. MRO should concern more for evaluating the vendors to align with the strategies to get quick turnaround time with the right quality product. Supplier selection is the objective of this research by analyzing the selection criteria at Industrial Gas-Turbine maintenance. The highest priority is the vendor effectiveness followed by the quality, cost, risk management. The highest weight is based on the priority of the supplier.
\end{abstract}

Keywords. AHP, Delphi, supplier selection, industrial gas-turbine, maintenance, repair, and overhaul.

\section{Introduction}

Mega-Infrastructure spending initiative in Indonesia increase energy production and consumption, many investors in energy sectoral came to Indonesia, so there are many energy producer companies operate in Indonesia. Indonesia currently installed powerplant capacity almost reach $60 \mathrm{GW}$, including PLN and IPP plants, private power utilities, and those under non-oil operating permits. There are four primary sources of power in Indonesia, namely coal, gas, oil, and renewables. Based on the source above, gas-turbine growth annually. Longterm maintenance commitments for any generating equipment are a crucial thought and require careful, advanced consideration as modern unit contracts are arranged. Combustion and hot gas path parts are of specific concern. They carry a high-cost tag stemming from the high-tech, space-age innovation coatings connected to resist an excellent warm introduction. These parts are regularly beneath visible assurance, are delivered in little batches, and require

\footnotetext{
* Corresponding author: yordianfachrie@gmail.com
} 
skilled labor for installation and maintenance. Equipment accessibility may be a primary thought when deciding a supply chain technique for gas-fired turbines.

Along with availability comes the requirement for top-notch repair facilities qualified to restore the parts removed during each maintenance event. The growth and competition of companies engaged in the gas-turbine industry, as well as the existence of high safety and quality standards, encourage power generation companies to improve their managerial and operational systems continuously. With these conditions, it is essential for maintenance, repair, and overhaul, to consider and prepare everything in order to meet customer demand and quality standards. This activity is done to one of them by increasing the quality and capabilities. Supply chain management is a management of activities in order to obtain raw materials into semi-finished goods and finished goods until the distribution of these products to end consumers. Designated suppliers are demanded to be able to provide goods on time and to follow company quality standards. Besides, suppliers have been recognized as the best intangible assets that any business organization can have.

Based on the described phenomenon, how to choose the best supplier? Numerous models have been created to provide supplier selection to simplify the decision-making process. However, most of them do not consider the uncertainty and complexity of choice-making legitimately. It is troublesome to measure the choice criteria, and situations are uncertain. Thus, there is a requirement for creating a precise provider determination prepare for distinguishing and prioritizing pertinent criteria and assessing the trade-offs between quality, cost, and delivery criteria. Using a systematic literature review and Delphi method, a comprehensive list of supplier attributes is found faster and reaches the consensus before implemented in the fuzzy analytical hierarchy process (FAHP).

\section{Literature Review}

\subsection{Decision Making}

Every level and field of organization makes decisions. Experts define decisions in a variety of ways. Decisions interpreted as the choice between two or more alternatives [2]. Others define decisions as to the choice of strategy or action. Thus, decision making can be defined as the art of choosing strategies or actions (actions) that are believed to provide the best solutions to existing problems. Decision making is a comprehensive process, not just a simple act of choosing one among several alternatives. The decision-making process is structured in eight steps, which include identifying problems, choosing alternatives, and evaluating the effectiveness of decisions. The stages in the decision-making process approach are as follows [2]:

1. Recognize a problem

2. Identify decision criteria

3. Allocate criteria weights

4. Arrange alternatives

5. Analyze alternatives

6. Choose an alternative

7. Implement selected alternatives

8. Evaluate the effectiveness of the decision

\subsection{Suppliers Strategy}

Purchasing plays a vital role in supply chain management through the selection of appropriate suppliers. Many companies treat suppliers as unnecessary parts, so they do not payattention 
to their cooperative relationships with suppliers [3]. Suppliers are one of the most important links to a company's success. The company will not be successful in producing products with low cost and high quality without wise selection and maintenance of competent suppliers [4]. Supplier selection plays the most crucial issue faced by manufacturing companies in a competitive environment. The price of raw materials in the industry is the most substantial part of the cost of producing finished goods, and the selection of the right supplier will significantly reduce the purchase cost [5]. In order to be a successful company, the company must include suppliers in the company organization. Below is a supply chain strategy for suppliers [6]:

1. Negotiations with many suppliers

- Suppliers must be able to respond to requests.

- Choose the supplier with the lowest price.

- For a long-term relationship.

- Suppliers are responsible for providing the required technology, expertise, ability in cost estimation, quality, and delivery competencies.

2. Long-term partners (few suppliers)

- Understand the objectives of the company's buyers and end consumers.

- The integration of suppliers, production, and distribution requires production readiness.

3. Vertical integration

- Producing itself a product that has been purchased or buying directly from a supplier (distributor).

- Reducing costs and delivery time.

- Suitable for companies that have a significant market share and can manage suppliers purchased.

- Having technology risk is a technology that is changing rapidly and requires a substantial investment to respond to the new wave of technology.

4. Keiretsu (A combination of a few suppliers and vertical integration)

- The network implemented in Japan is to make suppliers part of a coalition of companies.

- Keiretsu members get long-term guarantees, partners, provide technical expertise, and stable product quality.

- Keiretsu members have a second, third supplier, and so on.

Within the supplier selection methods, numerous multi-criteria choice-making strategies have been connected, such as fuzzy TOPSIS, analytic network process (ANP), data envelopment analysis (DEA), analytic hierarchy process (AHP), and mathematical programming [7]. Another approach that can be assessed and applied to the supplier-selection choice-making handle could be a strategy that is coordinating numbers programming, objective programming, stochastic strategy, fuzzy set hypothesis, and fuzzy numerous quality choice making (FMADM) into one comprehensive approach. There is some development on the supplier selection and evaluation model. The fuzzy Delphi strategy (FDM), i.e., an integration of the fuzzy concept and the Delphi strategy, requires as it were a little overview test to get an objective and sensible result. With this strategy, time and costs of collecting surveys can be diminished, and specialists' suppositions can be kept as they are without being twisted [8].

AHP is one of the foremost commonly utilized strategies of estimation for numerous criteria through pair-wise comparisons and depending on the subject judgment in scaling the priority for many fields such as selection, evaluation, planning and development, decision making, or forecasting. AHP will be simple methods and captures both qualitative and quantitative criteria also use in both criteria comparison, and individual aspects within each criterion can be tackled. However, the disadvantages will be inconsistency and need 
additional involvement to clarify the variables, to deal with the problem of fuzziness, the fuzzy set theory is adopted. This method is known as the Fuzzy Analytic Hierarchy Process (FAHP), which combines fuzzy theory, and AHP is introduced by Chang (1996) that combines the fuzzy concept with the AHP method using a triangular fuzzy number (TFN). Fuzzy AHP is considered better in describing vague decisions than AHP. The fuzzy AHP method provides more flexible, comprehensive, and realistic results, especially for the criteria that have qualitative nature [9]. It is crucial to ensure that the opinions given come from experts who are full of skills, harmony, and prudence when using the Fuzzy AHP method. Fuzzy AHP with Delphi can be an effective problem-solving methodology that uses almost clear application decisions by taking into account the uncertainty of one's judgment and will increase the questionnaire recovery rate and will clarify the invertible fuzziness in interviews with the help of the expert to obtain more reasonable and proper responses [7].

\section{Research Methodology}

This research will be based on a case study in the maintenance repair and overhaul company, which is a case in the industrial gas-turbine engine unit. A combination of the quantitative and qualitative methods will be used in the research, such as discussion by using the Delphi method, and fuzzy analytical hierarchy process (F-AHP), to help answer the objectives of the research. Development of power services will be the base of the problem and basis of the research, power services business before and in the future will be snap in the research and will be explored and used as an additional reference to identify existing problems.

After the research objective defined, a literature review will be carried out under the terms and conditions of related research. Review and mapping were obtained to identify the criteria attributes used in the study. A summary of the criteria will be a reference for the next process. Additionally, useful insights from references will be added to the research, such as the methods used and the number of respondents involved in this research.

The list of criteria attributes from the literature review result will be processed by involving some experts in the area using the Delphi method. Delphi Methods will reduce cost, and time for collecting questionnaires will be reduced, and expert opinion and judgment will be kept without being twisted [7]. The Delphi methods goal will be consensus to pick the prioritize item will be listed before implementation in the F-AHP model, the variable that already consensus will be followed up by making pair-wise comparison questionnaire, according to AHP. A developed questionnaire will be distributed to gas-turbine maintenance providers management for empirical data in supplier selection. The result of the questionnaire will be analyzed to get some conclusions and recommendations.

\subsection{Source of data}

In this research, the data needed is obtained by the following methods:

1. Collecting data about the services list and the name of the supplier and the procurement system in the company

2. Conducting initial interviews with experts as relevant respondents in determining supplier criteria that have been adjusted to company policy, besides the criteria from several literature studies are used as a reference in the selection of supplier's selection criteria and sub-criteria

3. Make a questionnaire that is divided into three stages, namely:

- The first stage contains the main criteria compiled by sub-criteria. This questionnaire part aims to see the relationship and the importance level of the main criteria and sub- criteria prepared by the researchers of its application in the company. This stage also aims to explore respondents for criteria and (or) sub-criteria 
that need to be removed and (or) added.

- The second stage contains the pair-wise comparison between the main criteria and the pair-wise comparison between the sub-criteria in the main criteria. This questionnaire part intends to look at the relevance of the level of importance through priority weighting between criteria and between sub-criteria in the same criteria.

- The third stage contains the supplier's alternative comparison of all the sub-criteria. The purpose of this part of the questionnaire is to see the final weighting of the selected supplier.

4. After making the questionnaire, the next step is to spread the questionnaire to three departments involved in GMF. The distribution of this questionnaire was accompanied directly by the researchers. It was of an interview nature so that unclear questions in the questionnaire could be minimized.

5. Secondary data requests to relevant departments regarding the forecasting of raw material. Requested data for the boundary model and data that support the results of research in the form of performance reports or key performance indexes (KPI) regarding supplier service levels and rejection rates as well as assumptions about the level of price stability for validation of the processed data.

\subsection{Delphi Method}

The Delphi process that used in this research has three stages, brainstorming stage, grouping stage, and consensus stage. Explanation of the process each stage will be informed to the subject expert to ensure the process of supplier selection is effective. The user interface of this website is also simple, making it easier for the user to deliver survey objectives and facilitating participants to complete it. After selecting experts, the first step in this process is the brainstorming stage on the list of the supplier selection attributes from the literature review. It is expected to equalize the perception of experts to facilitate the next process. After that, experts were asked to add additional attributes related to industrial gas-turbine services that not listed in the literature. Then, the experts will choose the ten most critical attributes. The experts will choose the attributes that are suitable for industrial gas-turbine services.

In the last process, the experts are asked to categorize supplier selection attributes that have been selected, namely quality, price, reliability product, assurance, tangibles. The grouping result will be determined based on the dimensions in which a supplier is most often be categorized; the grouping process will be carried out for industrial gas-turbine services supplier attributes. The result of the list and grouping then informed to all experts. Then experts will be asked to select the preferences using a Likert scale from 1-5 (strongly disagree to strongly agree). The degree of the agreement will then be calculated to determine the level of consensus [10]. There are proposed three consensus measures combinatory:

1. $51 \%$ of experts at lease responding to the category strongly agree

2. The interquartile range below 1

3. Standard deviation below 1.5

If one of the three measurements above is not achieved, the consensus is not reached yet; then, the expert will reconfirm the option. 


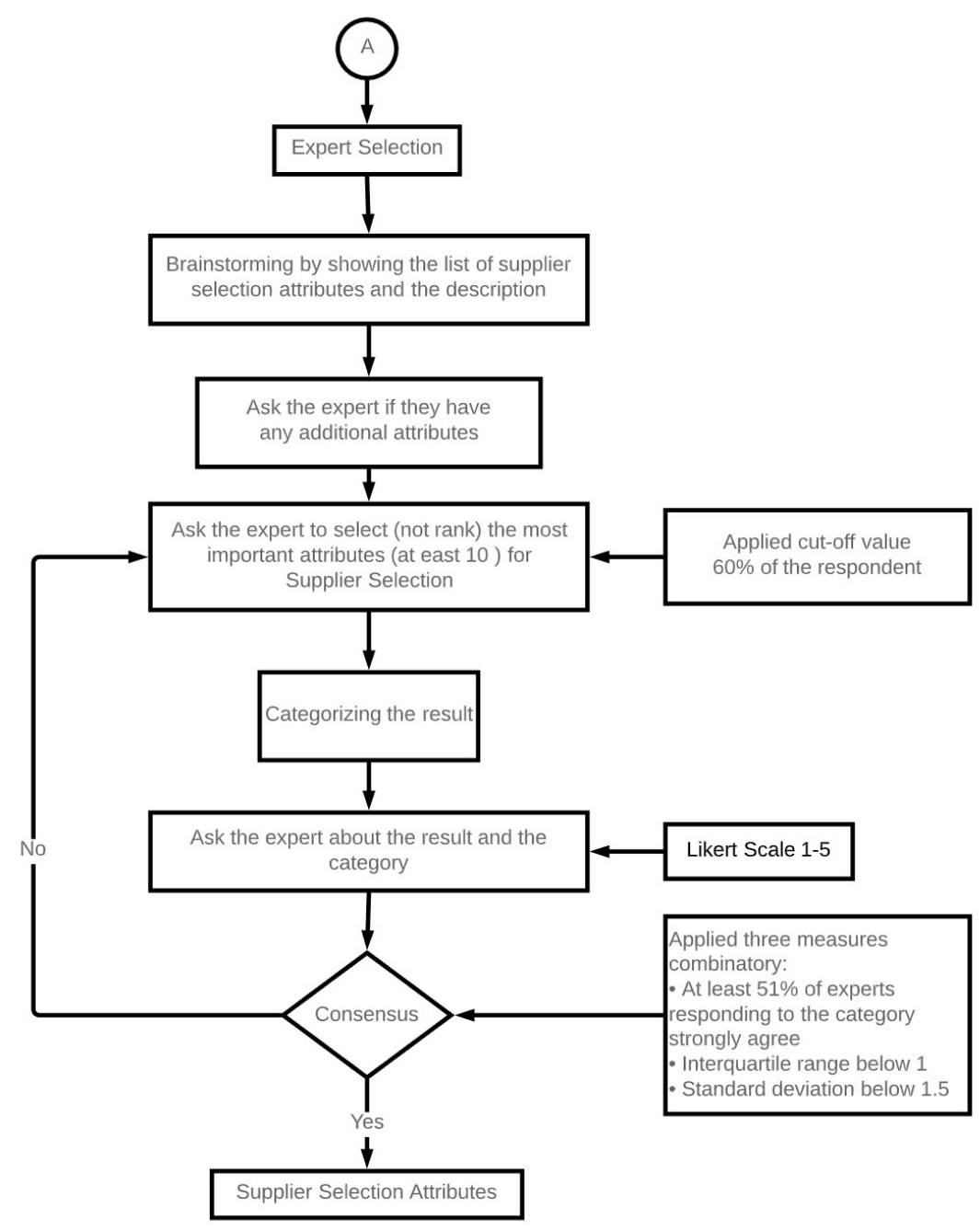

Fig.1 Delphi Method Process 


\subsection{Fuzzy Analytical Hierarchy Process (F-AHP)}

The use of F-AHP in determining the weight of the assessment can be explained briefly with the following steps:

1. Arrange and create a hierarchy of existing problems

2. Determine the assessment of pair-wise comparisons between criteria and alternatives to the objectives of the hierarchy

3. Change the weight of the pair-wise comparison judgment into fuzzy triangular numbers

4. If in assessing pair-wise comparisons using more than one respondent, then pairing comparisons are carried out by averaging fuzzy numbers to obtain a pair-wise comparison matrix

5. Calculating the matrix consistency test with the CR parameter $<10 \%$

6. From this matrix, we determine the value of the fuzzy synthetic extent for each criterion and alternative

7. Comparing the value of fuzzy synthetic extent

8. From the results of the comparison, the minimum value is taken

9. Calculation of weight vector normalization from the previous calculation.

Generally, data processing by using a fuzzy analytical hierarchical process will be done. Initially, the problem is described to the hierarchy of goals, criteria, and sub-criteria, so the ideas at the highest level are connected to the lowest level. This hierarchy can help to understand the problems and criteria that will affect the achievement of the main objectives [11].

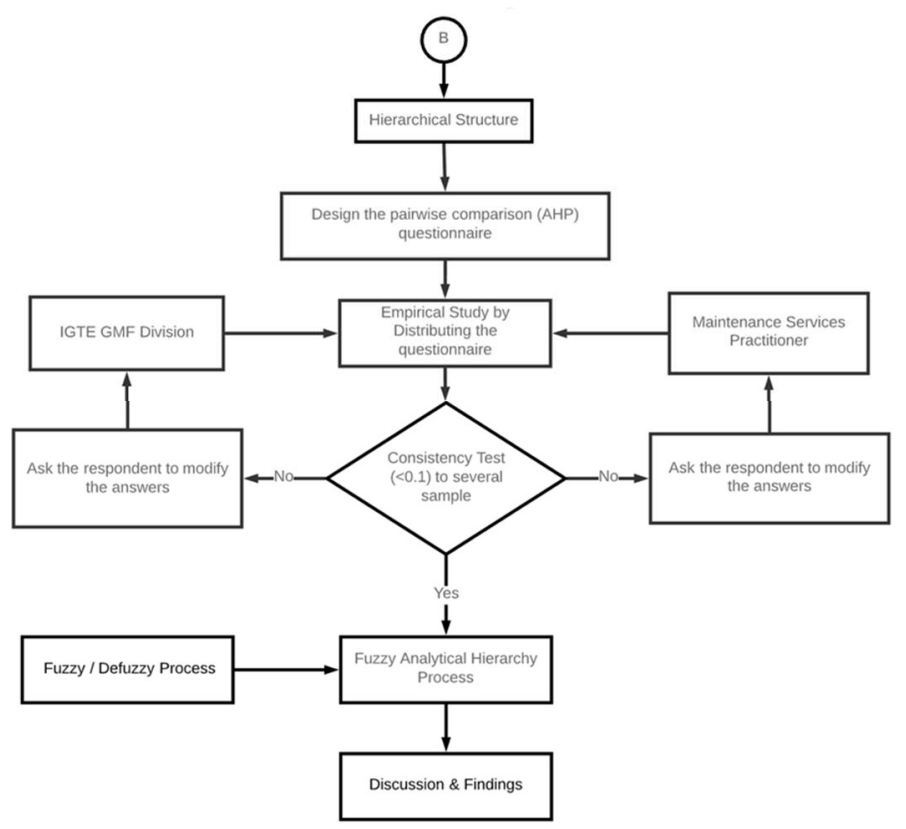

Fig. 2. Hierarchy Model tested on AHP. 
Table 1. Respondents Profile.

\begin{tabular}{|l|l|l|}
\hline \multicolumn{1}{|c|}{ No } & Institution - Sector & \multicolumn{1}{c|}{ Position } \\
\hline Respondent 1 & IGTE - Maintenance & Vice President \\
\hline Respondent 2 & IGTE - Maintenance & General Manager Engineering \\
\hline Respondent 3 & IGTE - Maintenance & Sr. Procurement / Tender Committee \\
\hline Respondent 4 & IGTE - Maintenance & Project Development Manager \\
\hline Respondent 5 & IGTE - Maintenance & Project Development \\
\hline Respondent 6 & IGTE - Maintenance & Market Development \\
\hline Respondent 7 & IGTE - Operator & Sr. Engineering \\
\hline Respondent 8 & IGTE - Operator & Market Development \\
\hline Respondent 9 & IGTE - Operator & Country Head \\
\hline Respondent 10 & IGTE - Operator & Project Development \\
\hline Respondent 11 & IGTE - Suppliers & Business Development \\
\hline Respondent 12 & IGTE - Suppliers & GM Business Development \\
\hline
\end{tabular}

The next stage of the research is setting priorities among the criteria or determinants that identified before in general. This priority setting will give affected the result of the questionnaire we gave to the respondent. F-AHP then used to finalize the prioritization process to find the significance of a set of each factor and sub-factors shown in the hierarchy. From the literature review, most topics of deployment F-AHP on cases related to industrial gas-turbine maintenance are to find out the best supplier attributes.

Table 2. Saaty's scale for AHP.

\begin{tabular}{|c|c|}
\hline Scale & Interpretation \\
\hline 1 & Equally Important \\
\hline 3 & Moderately more important \\
\hline 5 & Strongly more important \\
\hline 7 & $\begin{array}{l}\text { Very strongly more } \\
\text { important }\end{array}$ \\
\hline 9 & Extremely important \\
\hline $2,4,6,8$ & $\begin{array}{l}\text { The value between two } \\
\text { options close together }\end{array}$ \\
\hline
\end{tabular}

We then need to evaluate factors in the hierarchy by comparing one factor to another factor at a time; to find their influence of factors in the hierarchy, we can use a 1-9 scale as proposed by We can see a description of this scale in Table 2 . The next step is to evaluate and converting the result to numerical values for further data processes. We then need to make a pair-wise judgment, then continue converting it to the pair-wise matrix. After we raise a pair-wise matrix, we will need to gain a normalized matrix and calculated the eigenvector to represents the weight of the importance.

To be more effective, before the matrix is changed over to a fuzzy matrix, the consistency of expert judgment on paired comparison matrices is evaluated. The conventional AHP 
approach is utilized to test the consistency of firm matrices (12). Consistency index (CI), random index (RI), and consistency ratio (CR), it is proposed to test the consistency of a positive reciprocal matrix, which is defined as:

$$
C I=\frac{\lambda \max -n}{n-1}
$$

(n) represent the number of evaluating factors, and ( $\lambda$ max) represent the maximum eigenvalue of the matrix. The Consistency Ratio is defined in equation 2:

$$
C R=\frac{C I}{R I}
$$

(RI) represent the average value of the CI from $n$ Number positive reciprocal pair-wise comparison matrices in relation with entries were randomly generated using the 1-9 scale describes in table 2. Meanwhile, Table 3 provides RI range values for different $\mathrm{n}$ number.

Table 3. Values of the random index for different matrix order.

\begin{tabular}{|l|c|c|c|c|c|c|}
\hline \multicolumn{7}{|c|}{ Relationship between n and RI. } \\
\hline $\mathrm{n}$ & $1-2$ & 3 & 4 & 5 & 6 & 7 \\
\hline $\mathrm{RI}$ & 0 & 0.58 & 0.9 & 1.12 & 1.24 & 1.32 \\
\hline
\end{tabular}

It is critical to pay attention to $\mathrm{CR}$ esteem. In case $\mathrm{CR}$ is equal to 0 , at that point able to take the respondent's answers are consistent; In case CR rises to 1, at that point, the answers are inconsistent.

In general, based on Thomas Saaty's theory, we can interpret answers within the range of 0.1-0.15 are considered consistent enough to be acceptable [9]. Under the condition of CR value above 0.15 , it is recommended to repeat evaluation until we get acceptable consistency. However, in real AHP practice, a comparison matrix usually giving poor/weak consistency, so keep repeating the evaluation until getting acceptable consistency can be difficult. In this study from 20 questionnaire responses, only 13 responses are valid for CR value under 0.1 and will be used in further result and analysis.

Next, usage of the eigenvector method, we then make a pair-wise comparison with a high level of consistency value to make a combined consolidated decision matrix to obtain the result. The weighted geometric mean of the decision matrix factors, which is expressed as the following equation 3 :

$$
C_{i j}=\exp \frac{\sum_{k=1}^{n} w k \operatorname{In} a_{i j(k)}}{\sum_{k=1}^{n} w k}
$$

Where " $\mathrm{C}$ " is the consolidated decision matrix and " $\mathrm{k}$ " as the number of participants' inputs to obtain the aggregated group result (10). After going through all processes, we can generate a numerical weight act as relative significance to be derived for each factor; this allows the factors to be compared with one another consistently and rationally. The consensus ratio among the respondents can be calculated using the Shannon alpha and beta entropy. The consensus indicator ranges from $0 \%$ (no consensus between experts) to $100 \%$. The AHP consensus ratio "S" calculated using the following equation 4 :

$$
\begin{array}{r}
S=\frac{M-\exp \left(H_{\propto \min }\right)}{\exp \left(H_{\gamma \max }\right)} / \frac{1-\exp \left(H_{\propto \min }\right)}{\exp \left(H_{\gamma \max }\right)} \\
\text { with } M=\frac{1}{\exp \left(H_{\beta}\right)}
\end{array}
$$

The responses accumulated from the questioner and empirical study will then be analyzed using the Analytic Hierarchy Process to assess the dominant parameter and correlation of each parameter involved in the decision to develop renewable projects. 


\section{Result and discussion}

To meet the objective of the research and to increase productivity in focus group discussion, several requirements need to be fulfilled in choosing participants. The first requirement is selected person should know the issue and topics and have a deep understanding that could give the best viewpoint and solution on the issue and could improve data collection quality. Second, the participant status level needs to be the same; in a mixed level group, the discussion will be dominated by the higher status and will need to encourage lower status level to meet the same participation level. The third requirement is to have a fair representative sample of persons to participate in the focus group discussion to minimize skewed data. It needs selecting participants that reflect the demographic characteristic of the target group, which depends on the issue of the group discussion such as age, department, and gender. Based on the research, since it is related to the company's strategic decision and the unit is relatively new, we choose key employees. They have a minimum of 3 (three) years' experience from several departments or units involved in the industrial gas-turbine engine decision-making.

\subsection{Supplier Attribute Selection}

Explanation of the process each stage will be informed to the subject expert to ensure the process of supplier selection is effective. The user interface of this website is also simple, making it easier for the user to deliver survey objectives and facilitating participants to complete it. After selecting experts, the first step in this process is the brainstorming stage on the list of the supplier selection attributes from the literature review. It is expected to equalize the perception of experts to facilitate the next process. After that, experts were asked to add additional attributes related to industrial gas-turbine services that not listed in the literature. Then, experts will choose the ten to twenty most critical attributes. Experts will choose the attributes that are suitable for industrial gas-turbine services. In the last process, experts will be asked to categorize supplier selection attributes that have been selected, namely quality, price, reliability product, assurance, tangibles. The grouping result will be determined based on the dimensions where the supplier is most often be categorized, and the grouping process will be carried out for industrial gas-turbine services supplier attributes.

Table 4. Delphi Stage 1.

\begin{tabular}{|c|l|r|c|}
\hline No & Supplier Selection Attributes & Time Selected & $\mathbf{\%}$ \\
\hline 1 & Material Price & 12 & $100 \%$ \\
\hline 2 & Discount & 12 & $100 \%$ \\
\hline 3 & Product Reliability & 12 & $100 \%$ \\
\hline 4 & Product Certification & 12 & $100 \%$ \\
\hline 5 & Incidental Delivery & 12 & $100 \%$ \\
\hline 6 & Terms of Payment & 10 & $83 \%$ \\
\hline 7 & Price Transparency & 10 & $83 \%$ \\
\hline 8 & Product Consistency & 10 & $83 \%$ \\
\hline 9 & Delivery Reliability & 10 & $83 \%$ \\
\hline 10 & Warranties & 10 & $83 \%$ \\
\hline 11 & Supplier Responsiveness & 10 & $83 \%$ \\
\hline 12 & Technical Support & 10 & $83 \%$ \\
\hline
\end{tabular}




\begin{tabular}{|r|l|r|r|}
\hline 13 & Conformation to Specification & 10 & $83 \%$ \\
\hline 14 & Price Stability & 10 & $83 \%$ \\
\hline 15 & Expediting & 10 & $83 \%$ \\
\hline 16 & Handling of Complaints & 9 & $75 \%$ \\
\hline 17 & Knowledge Management & 8 & $67 \%$ \\
\hline 18 & Long-term Relationship & 8 & $67 \%$ \\
\hline 19 & Company Reputation & 8 & $67 \%$ \\
\hline 20 & Inventory Cost & 7 & $58 \%$ \\
\hline 21 & Integrity & 6 & $50 \%$ \\
\hline 22 & Product Durability & 5 & $42 \%$ \\
\hline 23 & Attitude & 5 & $42 \%$ \\
\hline 24 & Impression & 5 & $42 \%$ \\
\hline 25 & Product Development & 4 & $33 \%$ \\
\hline 26 & Labor Relation & 3 & $25 \%$ \\
\hline 27 & Vendor Financial Position & 2 & $17 \%$ \\
\hline
\end{tabular}

Table 5. Delphi Stage 2.

\begin{tabular}{|c|c|c|c|c|c|}
\hline Supplier Attributes & Cost & Services & Quality & Organization & Delivery \\
\hline Material Price & 12 & & & & \\
\hline Terms of Payment & 12 & & & & \\
\hline Price Transparency & 12 & & & & \\
\hline Discount & 12 & & & & \\
\hline Product Reliability & & & 12 & & \\
\hline Product Consistency & & & 12 & & \\
\hline Delivery Reliability & & 1 & & & \\
\hline Warranties & & 9 & 3 & & \\
\hline Supplier Responsiveness & & 10 & & & \\
\hline Technical Support & & 10 & & 12 & \\
\hline Long Time Relationship & & & 2 & & \\
\hline Company Reputation & & & & & \\
\hline Conformation to Specification & & & & & \\
\hline
\end{tabular}




\begin{tabular}{|c|c|c|c|c|c|}
\hline Knowledge Management & & 1 & & 11 & \\
\hline Price Stability & 12 & & & & \\
\hline Product Certification & & & 12 & & \\
\hline Handling of Complaints & & & & 12 & 12 \\
\hline Expediting & & & & & 12 \\
\hline Incidental Delivery & & & & & \\
\hline
\end{tabular}

Table 6. Delphi Stage 3 with $93 \%$ consensus.

\begin{tabular}{|c|c|c|c|c|c|}
\hline \multicolumn{6}{|c|}{ Supplier Attributes } \\
\hline \multirow{1}{*}{ Criteria } & Cost & Services & Quality & Organization & Delivery \\
\hline & Material Price & $\begin{array}{c}\text { Warranties } \\
\text { Period }\end{array}$ & $\begin{array}{c}\text { Product } \\
\text { Reliability }\end{array}$ & $\begin{array}{c}\text { Long Term } \\
\text { Relationship }\end{array}$ & $\begin{array}{c}\text { Delivery } \\
\text { Reliability }\end{array}$ \\
\cline { 2 - 6 } & $\begin{array}{c}\text { Payment } \\
\text { Terms }\end{array}$ & Responsiveness & $\begin{array}{c}\text { Product } \\
\text { Consistency }\end{array}$ & $\begin{array}{c}\text { Company } \\
\text { Reputation }\end{array}$ & $\begin{array}{c}\text { Incidental } \\
\text { Delivery }\end{array}$ \\
\cline { 2 - 6 } Criteria & Price Stability & Tech Support & $\begin{array}{c}\text { Conformation } \\
\text { to Specification }\end{array}$ & $\begin{array}{c}\text { Knowledge } \\
\text { Management }\end{array}$ & Distance \\
\cline { 2 - 6 } & Discount & & & & Expediting \\
\cline { 2 - 6 } & $\begin{array}{c}\text { Price } \\
\text { Transparency }\end{array}$ & & & & \\
\hline
\end{tabular}

\subsection{Supplier Selection}

After calculating the results of the weighting of the rounds performed in each of the criteria, sub-criteria, and suppliers, we can find the final weight of suppliers per each sub-criterion. The weight of the final supplier in this sub-criterion can then be multiplied by the weight of the main criteria to obtain the final supplier's results. The following is a table that lists the weights and priority values for each alternative criteria, sub-criteria, and supplier.

Table 7. Supplier attributes and selection weight.

\begin{tabular}{|c|c|c|c|c|c|c|}
\hline Dimension & Cost & Service & Quality & Organization & Delivery & \multirow{2}{*}{ Final Weight } \\
\cline { 1 - 6 } Criteria Weight & 0,3023 & 0,1439 & 0,2069 & 0,1417 & 0,2052 & \\
\hline Supplier A & 0,3147 & 0,4313 & 0,2169 & 0,4890 & 0,3402 & 0,3412 \\
\hline Supplier B & 0,3818 & 0,4717 & 0,5339 & 0,3767 & 0,4838 & 0,4464 \\
\hline Supplier C & 0,3035 & 0,0970 & 0,2492 & 0,1340 & 0,1760 & 0,2124 \\
\hline
\end{tabular}




\section{Conclusion}

Based on the questionnaire's feedback of experts active in the field of industrial gas-turbine operation and maintenance, Factors affecting supplier attributes selection can be clarified. Each factor's importance level is calculated by multiplying each determinant's weight by the weight of the category of the determinant. Table 5 shows the results for all the factors.

A competitive price is placed at the top importance level, with $7.49 \%$, followed by delivery reliability with $7.48 \%$ and expediting with $7.11 \%$. Three of them are the top three factors identified by respondents in this research. The competitive price is crucial due to the market condition where the tender process will be searching for the lowest cost so that the competitive material price will be needed. The second factor identified as delivery reliability, after the price, the customer will be concern about the lead time, and most of the late delivery is affected by the material delivery. In some cases, the price is not that sensitive, but the lead time will be concerned. Because in some power generation companies, a one-day shutdown will be cost higher than the discount of the maintenance price. The third factor is expediting, again, about delivery times. In the maintenance process, sometimes late finding will occur, so we need to expedite the late finding procurement process to achieve the lead time process.

Collaboration with suppliers prevails in various matters such as quality improvement, design changes, and product specifications to foster long-term strategic alliance relations. Management's commitment emphasizes the direction the company will be taken, including regarding the formulation of policies to determine what strategic steps the company can take to sustain a long-term business with better competitiveness.

\section{References}

1. Keeley, Alexander Ryota and Matsumoto, Ken'ichi. Investors' perspective on determinants of foreign direct investment in wind and solar energy in developing economies - Review and expert Opinion, Journal of Cleaner Production (2017)

2. Robbins, S.P. and Coulter, M. Management, 8ed., NJ: Pearson Education, Inc. (2005)

3. Garoma, Diriba. Modeling and Analysis of Supplier Selection Method Using Analytical Hierarchy Process (AHP), Sciences, Technology and Arts Journal (2014)

4. W Ho, X Xu, PK Dey. Multi-criteria decision making approaches for supplier evaluation and selection: A literature review, Operational Research (2010)

5. Govindan,Rajendan,Sarkis. Multi criteria decision making approaches for green supplier evaluation and selection: a literature review, Journal of Cleaner Production (2016)

6. J Haizer, B Render, Principles of operations management, Pearson (2004)

7. F Tahriri, M Mousavi, SH Haghighi. The application of fuzzy Delphi and fuzzy inference system in supplier ranking and selection, Journal of Industrial Engineering (2014)

8. M Bouzon, $\mathrm{K}$ Govindan, CMT Rodriguez, Identification and analysis of reverse logistics barriers using fuzzy Delphi method and AHP, Journal of Resource and Conservation (2016)

9. Huang, Han-Chen. A most advantageous bid evaluation model based on fuzzy analytic hierarchy process for supplier selection, International Journal of Organizational Innovation (2017)

10. Giannarou, Zervas, Using Delphi technique to build consensus in practice, International Businees and Sciences (2014)

11. Saaty, T.L. The Analytic Hierarchy Process: Planning, Priority Setting, Resource Allocation. . New York : McGraw-Hill, (1980) 
12. Hsu, Huang. Evaluating the service requirements of Taiwanese international port distribution centres using IPA model based on fuzzy AHP. International Journal of Shipping and Transport Logistics (2014)

13. Dhochak, Monika and Kumar Sharma, Anil. Identification and prioritization of factors affecting venture capitalists' investment decision-making process - An 
analytical hierarchal process $(A H P)$ approach, Journal of Small Business and Enterprise Development (2016) 